\title{
La violación sexual a través del análisis de tres casos en Los pasajeros del viento
}

\author{
Raping through the analysis of three \\ cases in Passengers in the Wind
}

\author{
Argelio García
}

Argelio García es biólogo, ha escrito artículos sobre cómic en El diario de Avisos de Tenerife, Tebeolandia y CuCo, Cuadernos de Cómic. Desde 1983 es miembro del jurado de los Premios de la Historieta de El Diario de Avisos.

Fecha de recepción: 12 de enero de 2018

Fecha de aceptación definitiva: 23 de mayo 2018 


\title{
Resumen
}

La violación sexual es un acto que provoca la indignación y el rechazo de la sociedad. El código penal castiga, severamente, al violador pero, frecuentemente, la víctima no denuncia a su agresor por miedo a ser culpabilizada. En este trabajo, se analizan tres casos de violación grupal narrados en la obra Los pasajeros del viento porque su autor, François Bourgeon, trata a las víctimas como sujetos, no como objetos. En cada caso se expone la situación previa a la violación y la causa que la provoca; se describe la escenificación de la violación y se muestra el impacto que sufren las víctimas.

Palabras clave: Los pasajeros del viento, François Bourgeon, feminismo, violación sexual, siglo XVIII.

\begin{abstract}
Rape is an act that causes indignation and rejection from society. The criminal code penalizes the violator; however, the victim often does not report her attacker for fear to be blamed. In this article, we analyse three cases of gang rape narrated in the work Passengers on the wind where his author, François Bourgeon, treats victims like active subjects, not as objects. In each case, the situation prior to the rape and the reasons behind it are discussed; it describes the dramatization of the event, and it shows the impact on the victims.
\end{abstract}

Keywords: Passengers on the wind, François Bourgeon, feminist, rape, eighteenth century.

\section{Cita bibliográfica}

García, A. «La violación sexual a través del análisis de tres casos en Lospasajeros del viento», en CuCo, Cuadernos de cómic n. ${ }^{\circ} 10$ (2018), pp. 84-110 


\section{Introducción}

En el siglo Xvin la educación de una joven se podía realizar en tres instituciones, el convento, la escuela elemental y el internado laico, pero la enseñanza impartida estaba muy alejada de la de los varones. ${ }^{1}$ En la edad adulta, la mujer estaba sometida al poder masculino y legalmente era considerada un ser inferior. ${ }^{2}$ Además, la ciencia de la época presentaba a la mujer como un ser voluptuoso, ${ }^{3}$ por lo que su asociación a la lujuria estaba normalizada. ${ }^{4}$ Con estas premisas y bajo un estamento jurídico compuesto exclusivamente por hombres, la interpretación de los hechos ante un caso de violación sexual dejaba pocas esperanzas a una resolución favorable a la mujer.

Actualmente, se considera que todo acto sexual impuesto a otra persona por la fuerza y sin su consentimiento es una violación. Esto incluiría también la coacción o la amenaza a la víctima, con medidas represoras o sancionadoras, para que no pueda impedir un acto sexual no deseado: «lo definitorio es, pues, que la mujer se perciba a sí misma objeto de agresión sexual, sean cuales sean las formas y circunstancias en que dicha agresión haya sido llevada a cabo». ${ }^{5}$ Hoy la mujer occidental dispone de recursos suficientes para defenderse, desde el punto de vista jurídico, ante una agresión sexual, pero esta protección, que le ofrece la ley, no evita que se produzcan las violaciones. En el informe Virage (Violances et rapports de genre), de 2015, se cita que «el número anual de personas, de 20 a 69 años,

1 «Sea cual fuere la escuela a la que la niña asista, no corre el riesgo de salir sabia. El convento, al igual que la escuela elemental, solo ofrece invariablemente una experiencia limitada del saber, tanto debido al tiempo que se le consagra como al pobre programa de conocimiento propuesto». En Sonnet, M. «La educación de una joven», en Duby, G. y Perrot, M. (eds.). Historia de las Mujeres 3. Del Renacimiento a la edad moderna. Madrid, Taurus Minor, 1993, p.153.

${ }^{2}$ La letra de la ley es la siguiente: «el marido tiene plenos poderes sobre su mujer y sobre los bienes de su mujer. Él tiene el derecho de exigir todos los deberes de sumisión que le son debidos a un ser superior». Slomanis, B. La morale féminine dans «Delphine» et «Corine» de Madame de Staël. [Tesis doctoral]. Montreal, Mcgill University, 1990, p. 8.

3 «La ciencia médica, al declarar que para las mujeres la satisfacción erótica era una necesidad biológica, reforzó [la] idea acerca de la voracidad de la sexualidad femenina». En Matthews, S. «El cuerpo apariencia y sexualidad», en Duby, G. y Perrot, M. (ed.). Op, cit., p. 98.

4 «[Las mujeres] encarnan en ellas mismas una corrupción superior a todas las demás y estaríamos tentados de llamarla corrupción ideal. El libertinaje de las pasiones perversas, la lujuria del mal». En Goncourt, E. y Goncourt, J. La Femme au Dix-Huitième Siécle. Paris, G. Charpentier, Editeur, 1882, p. 198.

5 Echeburua, E., Corral, P. y Sarasua, B. El Impacto psicológico en las victimas de violación. Departamento de Personalidad, Evaluación y Tratamientos Psicológicos, Universidad del País Vasco, (sin fecha), p. 57. Disponible en https://www.ehu.eus/documents/1736829/2028519/08+-+Impacto+psicologico.pdf 
víctimas de al menos una violación o una tentativa de violación se estima, en Francia, en 62.000 mujeres». ${ }^{6}$

Las violaciones sexuales continúan produciéndose pese la severidad de la leyes, tal y como sucedía en épocas pasadas; también las ordenanzas jurídicas durante el Antiguo Régimen condenaba severamente el delito de violación, pero la diferencia es que, en el siglo xviII, era poco perseguido por los jueces que «condenan y perdonan a un tiempo, oscilando entre la indulgencia y la represión, jugando con lo que en nuestros días sería una tolerancia inaceptable y una inaceptable ferocidad. La respuesta jurídica que se da a la violación es la repercusión hasta cierto punto de la respuesta jurídica que se da a la violencia ordinaria». ${ }^{7}$

Para el presente trabajo sobre la violación sexual se ha recurrido a la obra Los pasajeros del viento, ${ }^{8}$ porque su autor, François Bourgeon, no se limita a la mera exposición de la vertiente sexual de la violación sino que dirige sus esfuerzos a mostrar el impacto que sufren las víctimas y sus repercusiones psico-sociológicas. La originalidad, pues, de la obra de Bourgeon estriba en que si por un lado muestra la naturaleza y el comportamiento del violador, por otro lado da amplia voz a la víctima, lo que supone, en cierta medida, un reconocimiento de la mujer violada como sujeto frente a la cosificación y repudio de la sociedad. Además, el hecho de que la acción, aquí descrita, transcurra en un periodo próximo a la Revolución francesa de 1789, nos permite contrastar la visión sobre la violación sexual entre el Antiguo Régimen y la actualidad.

En Los pasajeros del viento se citan distintas formas de agresión sexual como es la violación masculina, en la prisión, (Le ponton. Glénat, 1980, p. 10) o la utilización de esclavas africanas como objetos sexuales por hombres de raza blanca (Le bois d'ébène. Glénat, 1984, pp. 12-13). En este trabajo, vamos a centrarnos en solo tres casos de violación heterosexual que sufren dos de las protagonistas de la obra: Isa y Mary.

En la presentación de cada caso de violación se atenderá al protocolo siguiente: en primer lugar, se expone la situación previa a la violación y la causa que la provoca; en segundo lugar, se describe el modo en que se presenta gráficamente la violación; y, en tercer lugar, se analiza el impacto del trauma a través de las palabras de la víctima. Además, en la exposición se tiene en cuenta el contexto histórico y la legislación jurídica vigente durante el Antiguo

${ }^{6}$ Hamel, C. et al. Viols et agressions sexuelles en France: premiers résultats de l'enquête Virage. Population \& Sociétés, n.o 538, (2016), p. 2. Disponible en https://www.ined.fr/fichier/s_rubrique/25953/538.population. societes.2016.novembre.fr.pdf

7 Vigarello, G. Historia de la violación: siglos Xvi-Xx. Madrid, Ediciones Cátedra y Universitat de València, 1999, p. 17.

${ }^{8}$ La obra de Los Pasajeros del viento consta de siete álbumes publicados. El primer ciclo consta de cinco libros publicados por la editorial Glénat bajo los títulos siguientes: La fille sous la dunette (1979), Le ponton (1980), Le comptoir de Juda (1981), L'beure du serpent (1982) y Le bois d'ébène (1984). El segundo ciclo comprende dos tomos publicados por la editorial 12bis bajo un título común: La Petite fille Bois-Caïman (2009 y 2010). Narrada en dos tomos, Le sang des cerises será el tercer y último ciclo de la serie, la fecha prevista de aparición del primer volumen es a finales de 2018. 
Régimen, aunque en ningún caso se pretende elaborar un texto académico desde el punto de vista histórico o del derecho penal.

\section{Primer caso de violación. La violación de una menor, Isa}

\section{Contexto previo a la violación de la menor Isa}

Nacida a finales del siglo Xviı en el seno de una familia aristocrática, Isa comparte su niñez con una joven huérfana procedente de la pequeña nobleza: Agnes. Ellas viven en una mansión familiar en la campiña, al cuidado de una gobernanta, y sin recibir visitas de sus parientes.

El hecho de que las dos niñas se parecieran como dos gotas de agua y que en un crítico momento intercambiasen sus vestidos (única forma de diferenciarlas) va a provocar un hecho insólito. En la única visita que el padre de Isa, Simon de Roselande, hace a la mansión de la campiña, no reconoce a su propia hija y la enviará a un convento, creyendo que se trata de la compañera de su hija, y se lleva a la huérfana Agnes a vivir con él a la ciudad como si fuera su auténtica hija. ${ }^{9}$

Después de cinco años de internado en un convento, Isa, a los catorce años de edad, regresa a la vida social como dama de compañía de la ahora joven aristócrata Agnes de Roselande. En la fiesta del catorce cumpleaños de Agnes, se celebra un gran baile en el salón de la mansión de los Roselande. El hijo de Simon de Roselande, Benoît, recién nombrado capitán de marina, se presenta ante Isa (que en realidad es su hermana) con una frase galante: «¿Cómo ha podido mi padre tenerla tanto tiempo alejada de nosotros? Vuestra presencia ilumina este salón más calurosamente de lo que lo haría el sol del Caribe»; e Isa le contesta con una frase que se mueve entre la ironía y la melancolía. ${ }^{10}$ Benoît se ofrece como un auténtico amigo dispuesto a conocer el origen de la melancolía de la joven: «iSi tiene algún pesar, si alguien os hace daño! Dígamelo... Yo podría ayudarle. Siempre os he considerado casi como una hermana». Esta oferta toca una fibra sensible en el espíritu de Isa, como se expresa en su respuesta; primero plantea un enigma con el que intenta estimular la curiosidad de Benoï — «Su última frase me turba más de lo que usted pudiera pensar»—y después le propone la aceptación de un compromiso: « Es

9 García, A. «Lectura de Los pasajeros de viento desde una perspectiva feminista», en Cuco, Cuadernos de cómic, n. 8 (2017), pp. 58-59. Disponible en http://cuadernosdecomic.com/docs/revista8/Lectura de Los pasajeros del viento.pdf

${ }^{10}$ La frase de Isa es la siguiente: «Al no haber visto nunca el mar, no conozco el sol del que me habla, pero le diré que los habitantes de esta casa [en referencia a Simon de Roselande y a Agnes], en alguna ocasión, habrían necesitado estar un poco más iluminados». La comparación que hace Benoît entre la belleza de Isa que «ilumina» el salón y la luz del sol del Caribe es aprovechada por ella para asociar la iluminación al conocimiento. Evidentemente, Benoît no capta el sentido de la frase, pero el lector sí. Si Simon de Roselande hubiera estado «un poco más iluminado» y hubiera escuchado a Isa, antes de que la ingresara en el convento, se habría dado cuenta de que ella es su hija y ahora Isa no se encontraría frente a su propio hermano, Benoît, como si fuera un desconocido. 
usted capaz de guardar un secreto?». Benoît responde con una pregunta que, estrictamente, no tiene por qué considerarse una afirmación: «¿Es esa la pregunta que se le hace a un oficial de la marina?». Y, a continuación, hace una propuesta en forma de cita para entrevistarse con Isa: «Venga a mi habitación después del baile y la escucharé». (La fille sous la dunette, p. 26).

$\mathrm{Al}$ anochecer, Isa se presenta en los aposentos de Benoît y allí encuentra a un nutrido grupo de oficiales de la armada ebrios (FIG. 1). La puerta de la habitación se cierra y cuando Isa intenta percutir el picaporte para salir de la habitación se da cuenta de que esta ha sido cerrada con llave. Ella ruega que la dejen marchar pero Benoît le dice: «Me gustaría mucho, pero uno de nosotros acaba de extraviar la llave en los pliegues de su ropa... Ayúdenos a encontrarla y la puerta se abrirá». Esta ocurrencia de Benoît provoca la risa de los oficiales, que a fin de cuentas es una burla hacia una joven que apenas tiene defensa, y presagia la violación que va a acontecer (La fille sous la dunette, p. 26).
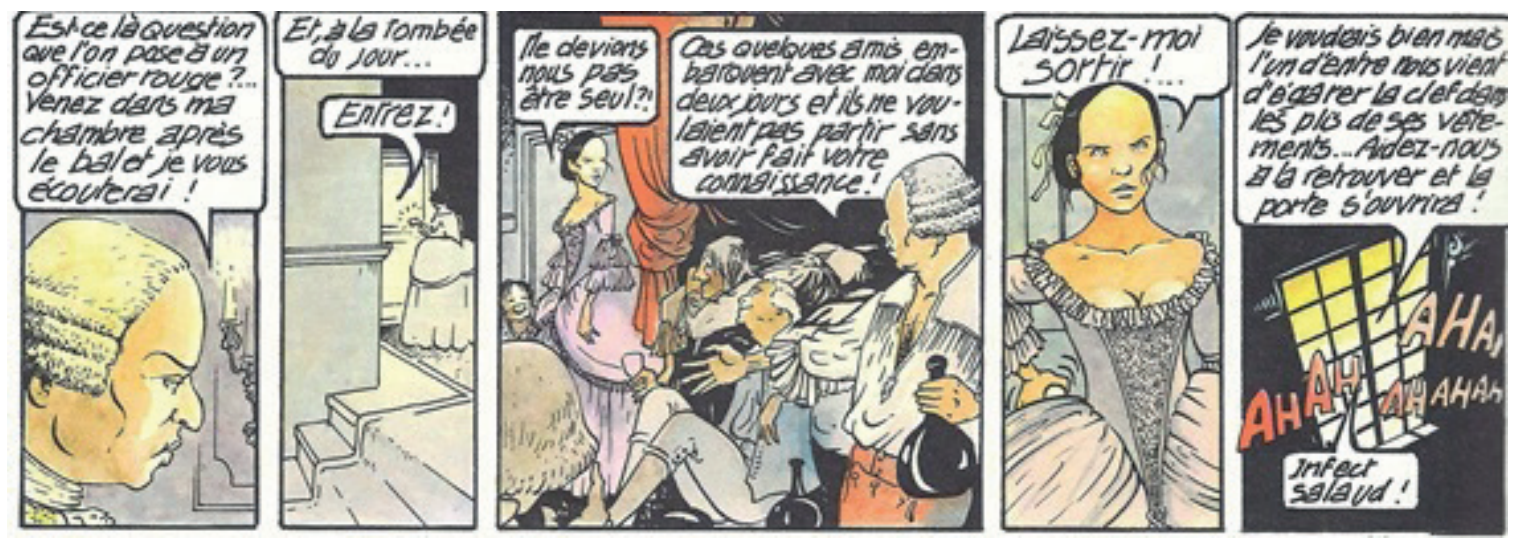

FIG. 1. Benoît de Roselande cita a Isa en su habitación para escuchar un secreto que ella desea confiarle. La presencia de oficiales de la marina ebrios en el lugar y la hora de la cita prueba la premeditación de Benoît en su deseo de forzar sexualmente a Isa. (La fille sous la dunette. Glénat, 1979, p. 26).

Esta última frase de Benoît y las risas de sus acompañantes aparecen como voces en off que surgen desde una ventana iluminada que ocupa toda la viñeta. Bourgeon utiliza este recurso del lenguaje del cómic para sacar al lector de la habitación y evitarle que sea testigo del abuso sexual.

Podríamos pensar que Isa cometió una imprudencia al aceptar la invitación de Benoît para conversar a solas en su cuarto privado. Ella podría dar la sensación de ser una joven voluble carente de un comportamiento responsable, frente a un hombre mucho mayor que ella. Él podría ver en esta visita un gesto de aceptación para participar en un juego sexual, ya que Isa habría mostrado falta de pudor y de moral. Sin embargo, dado que Isa y Benoît conviven bajo el mismo techo y que él había manifestado que consideraba a Isa como una hermana, esto justifica la visita de la joven, a una hora intempestiva, a la habitación privada de Benoît. 
La presencia de los oficiales en la habitación a la hora de la cita con Isa prueba la premeditación de Benoît en su deseo de forzar a Isa.

La violación llevada a cabo o promovida por una persona próxima a la víctima no es un hecho infrecuente. Hay estudios que señalan «que en un porcentaje muy elevado de los casos de violación la víctima y el agresor se conocían, eran vecinos o parientes». ${ }^{11}$

No debe extrañarnos que la víctima de la violación sea una menor, ya que la juventud no es un impedimento para que alguien sea considerado como un objeto sexual. Las violaciones que tienen víctimas de edad temprana no eran infrecuentes durante el Antiguo Régimen ${ }^{12}$ pero también se dan en la actualidad; así, la encuesta «Virage» realizada en Francia, en 2015, señala que «el $40 \%$ de las mujeres que han sufrido una violación o una tentativa de violación, lo han vivido en la infancia (menos de 14 años), 16\% durante la adolescencia (15 a17 años) y $44 \%$ después de los 18 años». ${ }^{13}$

Consecuencias de la violación de la menor Isa: ¿Un acuerdo económico es siempre posible?

La visualización de la violación de Isa es omitida en el relato y una elipsis nos lleva hasta una viñeta en la que se presenta a los actores en una posición relajada que sugiere al lector que la violación ha sido consumada (FIG. 2). En un primer término, Isa yace desnuda acostada en el suelo, en un estado de abandono y postergación que le da un aire de tristeza; a su alrededor los oficiales aparecen en el suelo en aparente desorden, aquí la cabeza de uno descansa junto a Isa, allí otro sentado en el suelo y detrás un tercero duerme acostado. Esta escena sugiere el agotamiento de los oficiales a causa del alcohol y su extenuación debido al esfuerzo en colmar sus impulsos sexuales. Si en la viñeta anterior la luz procedente desde el interior de la ventana alumbraba la oscuridad de la noche, en esta viñeta la ventana se vuelve a iluminar pero ahora desde el exterior. La luz del sol anuncia un nuevo día. Esta sutil forma de mostrar el paso del tiempo pone en evidencia que la violación de Isa se prolongó durante mucho tiempo (La fille sous la dunette, p. 27).

Ha amanecido y solo Benoît e Isa permanecen despiertos. Cabría preguntarse si, una vez pasado el furor del deseo y una vez satisfecho el placer sexual, Benoît pudiera tener conciencia del daño físico y moral causado a Isa o, al menos, tener la sensación de ser culpable de haber realizado un acto brutal y violento contra una joven. Sin embargo, Benoît responde a un patrón de comportamiento que refleja la mentalidad de su época.

Es ocioso decir que la primera característica de estas violaciones en la Francia antigua es la ausencia frecuente de sensación de violencia en el agresor, lo que las diferencia de otros

${ }^{11}$ Garrido, V. «Psicología de la violación», en Estudios de Psicología, Universidad de Valencia, n. ${ }^{3} 3$ (1989), p. 96.

12 Vigarello, G. Op. cit., pp. 88-94.

${ }^{13}$ Hamel, C. et al. Op. cit., p. 3. 


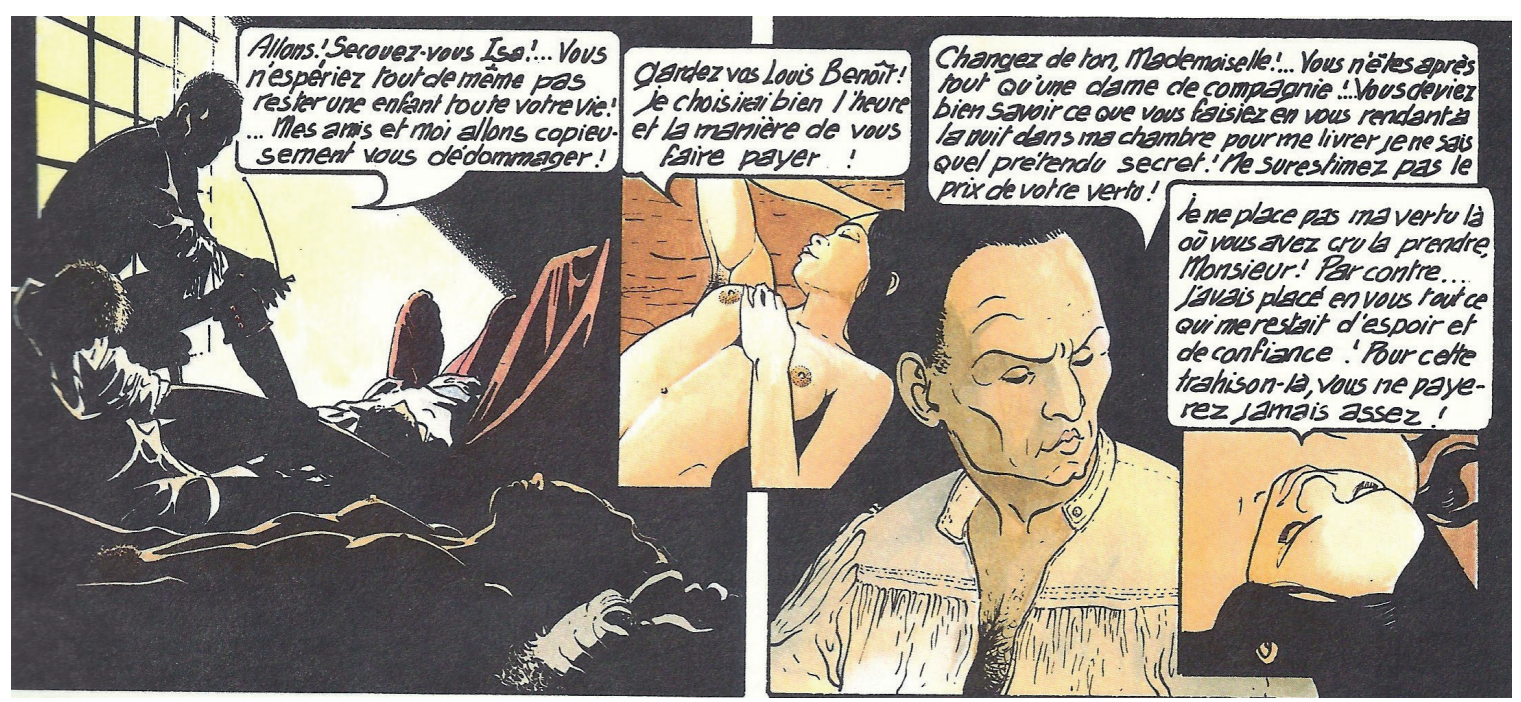

FIG. 2. Tras la violación grupal, Benoît de Roselande intenta un acuerdo económico para comprar el silencio de Isa. (La fille sous la dunette. Glénat, 1979, p. 27).

actos brutales. La imagen del placer borra la de la agresividad, imponiendo el deseo como una evidencia a la que la víctima está confusamente asociada... La resistencia de la mujer asombra incluso al agresor, que se convierte entonces en acusador. ${ }^{14}$

Benoît no se consideraría culpable de la violación de Isa porque, en la conciencia colectiva sobre la representación de la feminidad, se considera a la lujuria como un pecado innato en toda mujer. La lujuria se asocia al consentimiento de la mujer, enmascarando la violencia a la que ha sido sometida, y allí donde había una violación sexual podría verse un acto sexual consentido, ya que la violencia solo se ha aplicado para vencer el falso pudor inicial de la mujer. Este es, quizás, el mito más extendido sobre la feminidad: «las mujeres en realidad piden ser violadas de tal forma que sus quejas y acusaciones no son sino coartadas de sus deseos sexuales ocultos». ${ }^{15}$

El estado de postergación y abandono de Isa, acostada en el suelo y ausente de espíritu, incomoda a Benoît. Su silencio se le hace insoportable, ahora Isa, privada de su función de objeto sexual se convierte en un estorbo del que es mejor deshacerse cuanto antes. Para poner fin a la inquietante languidez de la joven, Benoît la apremia a que desaparezca de su habitación: «¡Vamos! ¡Muévase, Isa! Usted no pensaría, a pesar de todo, ser una niña toda la vida. Mis amigos y yo vamos a compensarle copiosamente». Esta es una realidad, o más bien una afrenta, ante la cual una mujer puede sucumbir: el silencio de una víctima

\footnotetext{
14 Vigarello, G. Op. cit., pp. 42-43.

15 Garrido, V. Op.cit., p. 97.
} 
de violación se puede comprar. ${ }^{16}$ En el Antiguo Régimen, los casos de violación podían resolverse si las partes llegaban a un acuerdo, por lo que era frecuente que «el arreglo [económico] se intenta[ra] prácticamente siempre, sobre todo cuando la víctima es socialmente inferior». ${ }^{17}$

Una denuncia, en esa época, podría incomodar al denunciado, pero tenía pocas posibilidades de prosperar, y la víctima contaba con sobrados motivos para querer ocultar los hechos padecidos: la mujer siempre era considerada sospechosa. «La mujer violentada solo existe cuando proyecta sus efectos sobre las gentes. Su voluntad debe ser vista, su defensa debe ser contada. Un público debe dar testimonio». ${ }^{18} \mathrm{La}$ exposición pública de una violación exponía a la víctima a la censura y a la indignidad, por lo que mas le valía callarse: «la originalidad del delito de violencia sexual durante el Antiguo Régimen es sobre todo la gran escasez de procesos: escasez de denuncias, escasez de condenas». ${ }^{19}$

Isa es una joven inexperta, apenas conoce el mundo en el que vive, es vulnerable, y no tiene a nadie que pueda protegerla o denuncie la agresión sufrida. Por ello, todo lo que puede hacer es guardar silencio. Si no lo hiciera, tendría muchas posibilidades de que ella, la víctima, fuera percibida como la causante de la violación y, por tanto, la violación dejaría de serlo para convertirse en un acto consintiente; Isa se vería expuesta a vivir bajo el estigma de la vergüenza y la condena social.

Una perspectiva persistentemente moralizadora del delito durante el Antiguo Régimen refuerza este silencio, envolviendo a la víctima en la indignidad del hecho, transformando en infamia el mero hecho de haber vivido con los sentidos y los gestos la transgresión condenada. Encontramos así una tendencia inevitable a denunciar a la víctima con independencia de las circunstancias, una dificultad constante para apartar las sospechas: la contaminación sufrida se asimila a una aceptación por parte de la mujer violada. ${ }^{20}$

El rechazo social frente a un delito moral hace que la víctima de una violación sea juzgada atendiendo más a una percepción de la lujuria que a la de un acto violento. Al no tener condición de sujeto, la violación de una mujer puede quedar como una violencia oculta. A fin de cuentas, la carencia de un comportamiento responsable o su falta de capacidad de decisión la priva de una defensa sólida, ya que sus argumentos serían fácilmente invalidados. La

16 Además del acuerdo económico entre el agresor y la familia de la víctima, también existía la posibilidad, tanto en el siglo XVIII como en épocas no tan pretéritas, de consensuar un matrimonio entre el violador y su víctima siempre que la diferencia social no fuera un impedimento. Aquí no haremos referencia al acuerdo matrimonial ya que este es muy difícil de alcanzar cuando se trata de una violación grupal perpetrada bien por el hermano de la violada y un grupo de oficiales de la marina, bien por una cuadrilla de marineros de muy bajo nivel ético y moral o bien por un grupo de esclavos de una colonia francesa.

17 Vigarello, G. Op. cit., p. 37.

18 Ibid., p. 64.

19 Ibid., p. 47.

${ }^{20}$ Ibid., p. 386. 
sensación de falta moral obstaculiza su capacidad de denuncia y contribuye a que la víctima de la violación prefiera callarse.

Sí, Isa se muestra ausente, pero las ofensivas palabras de Benoît la sacan de su ensimismamiento y desde su posición de debilidad, puesta de manifiesto en la quietud de su cuerpo, advierte a Benoît de que le hará pagar su ultraje, amenaza que expresa sin ira o cólera.

El hecho que la violencia ejercida sobre una mujer fuera tolerada en el Antiguo Régimen y que la diferencia de clase social en un litigio supusiera un valor protector para la aristocracia es lo que explica que ante la amenaza que Isa lanza a Benoît, este se permita reprenderla y recordarle quién es: «cambie de tono, señorita, después de todo usted es solo una dama de compañía».

A continuación, Benoît advierte a Isa de ser ella la única causante de la agresión que acaba de sufrir, basándose en que ninguna joven debería presentarse de noche en la habitación de un hombre: «Usted debía saber a lo que se exponía viniendo de noche a mi habitación para contarme yo no sé qué pretendido secreto». Esto es una insinuación que implicaría que Isa habría facilitado o deseado la relación sexual, por lo que su comportamiento es solo el reflejo de un consentimiento explícito. Este tipo de razonamiento es empleado para absolver judicialmente a un agresor sexual tanto en el Antiguo Régimen como hoy en día. Además, una vez consumado el acto sexual la mujer difícilmente escapa a la sospecha de que este acto ha sido realizado voluntariamente. "La dificultad, por ejemplo, de establecer la diferencia entre el consentimiento y el no consentimiento, con independencia del acto efectivamente realizado, la tendencia a reducir a la mujer que ha "realizado" el acto al estado de mujer consintiente». ${ }^{21}$ Finalmente, Benoît insiste en el arreglo económico pero haciendo constar que no va a pagar en exceso: «no sobreestime el precio de su virtud» le advierte a Isa.

De este modo, no se valora a Isa como una persona sino como una mercancía que tiene un alto valor específico a causa de su virginidad. Una vez que se ha roto el precinto del producto este disminuye su valor en el mercado.

La respuesta de Isa se corresponde con la de una mujer que trata de ser sujeto pese a haber sido tomada como objeto: «Yo no coloco mi virtud allí donde usted ha creído tomarla, señor» (La fille sous la dunette, p. 27).

Ciertamente, el concepto mujer no debería reducirse solo a sus órganos reproductores y de crianza. Isa posee un alto valor moral y pone la virtud femenina en otras cualidades de la mujer —intelectuales, artísticas, etcétera ${ }^{22}$ y no en la apariencia de un cuerpo que no puede permanecer inmutable como la estatua de una diosa griega.

${ }^{21}$ Garrido, V. Op. cit., p. 62

22 García, A. Op. cit., pp. 77-80. 
Consecuencias de la violación de la menor Isa: La convivencia entre el violador y su víctima

Un hecho frecuente entre las personas que han sido violadas por un familiar o una persona próxima a su entorno social es que tienen que convivir periódicamente con el agresor. En general, para la víctima de una violación la convivencia con su agresor es insoportable y trata de evitarla llevando una vida recogida y apartada; sin embargo, esto no es siempre posible y se generan sentimientos de odio, malestar o desprecio.

No sabemos con exactitud cuántas veces se encontraron Isa y Benôit después de que ocurriera la violación pero, unos años más tarde, Isa viajará en un barco comandado por Benoît. Ahora, ella es una persona más segura y tiene la entereza suficiente para burlarse de Benoît, incluso llega a manipularle y desafiar su autoridad.
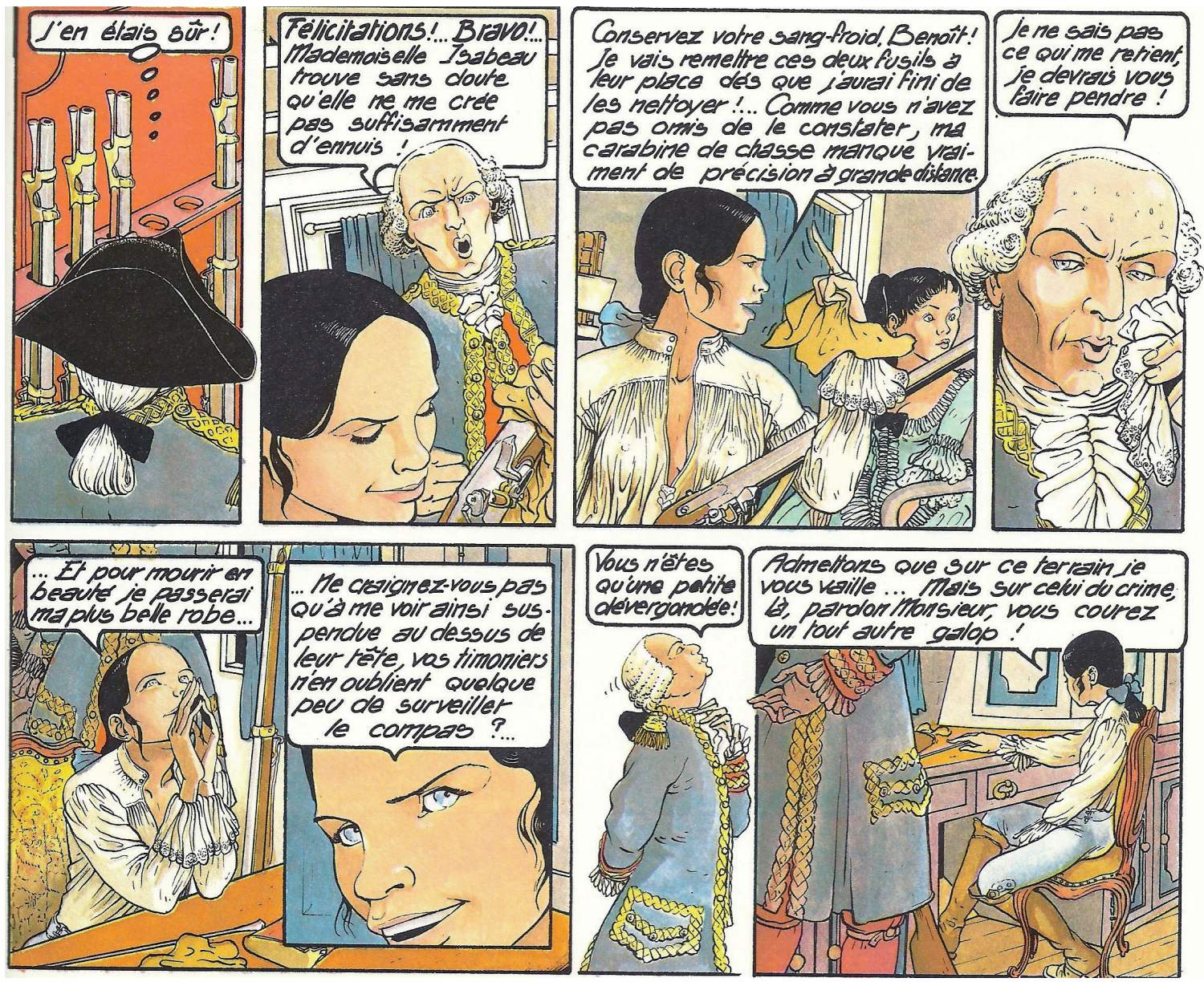

FIG. 3. La convivencia cotidiana entre el agresor, Benoît, y la víctima de una violación, Isa, no suele ser fácil. Isa, con el paso del tiempo, adquiere la entereza suficiente para desafiar y manipular a Benoît. (La fille sous la dunette. Glénat, 1979, p. 13). 
En las tres primeras viñetas de la Figura 3, se relata cómo Isa desafía la autoridad de Benoît al utilizar unos fusiles para salvar la vida de un joven bretón que Benoît deseaba ver muerto bajo la apariencia de un accidente. Benoît está fuera de sí y se desahoga, en la cuarta viñeta, diciendo: «no se lo que me retiene, debería colgarla [a Isa]». Isa se burla y le provoca anunciándole que se pondrá su mejor vestido para esa ocasión y le pregunta: «¿No teme que al verme así suspendida encima de sus cabezas, sus timoneles se olviden, un poco, de vigilar la brújula?» (La fille sous la dunette, p. 13). Después de esta fina ironía, propia de la elocuencia de Isa ${ }^{23}$ ella continuará con un discurso que no dará pábulo a Benoît, con el que conseguirá manipularle e imponerle su voluntad.

Pese al tiempo transcurrido, Isa no ha olvidado la agresión perpetuada por Benoît y no tiene inconveniente en mostrarle su malestar. Cuando Benoît señala que la ropa femenina realza la belleza de Isa mientras que la ropa masculina, que ella utiliza para pasearse por el puente del barco, la oculta, ella le contesta: «Solo lamento una cosa: no haberla llevado [la ropa masculina] el día en que nos conocimos». (La fille sous la dunette, p. 18).

Tras una serie de vicisitudes, Benoît descubrirá que Isa, en realidad, es su hermana, y que al violarla cometió, por tanto, un incesto. Al principio se siente perturbado pero su sentido de culpabilidad, por haber cometido una falta grave, no es comparable al que experimentara Edipo, que al saberse autor de un incesto y otros delitos se autocastiga: «arrancó los dorados broches de su vestido con los que se adornaba y, alzándolos, se golpeo con ellos las cuenca de los ojos» hasta quedarse ciego. La culpabilidad de Edipo tiene causas más profundas y diversas que las de Benoît, ya que incluye otros elementos, como él mismo expresa en la obra:

Edipo: No hubiera llegado a ser asesino de mi padre, ni me habrían llamado los mortales esposo de la que nací. Ahora, en cambio, estoy desasistido de los dioses, soy hijo de impuros, tengo hijos comunes con aquella de la que yo mismo — ¡desdichado! - nací. Y si hay una mal aún mayor que el mal, ése le alcanzó a Edipo. ${ }^{24}$

Edipo asume su culpa por las desgracias que ha provocado, sin saberlo, a su padre y a su madre, pero Benoît prefiere proyectar su culpabilidad sobre la persona a la que ha ultrajado sin saber que era su hermana. Él percibe a Isa como un ser peligroso dispuesto a acabar con él: «solo el espíritu de venganza anima a esta desgraciada [Isa]. Será imposible comprar su silencio, de apagar el escándalo» (La fille sous la dunette, p. 42). Este razonamiento de Benoît tiene su base en el hecho de que Isa no aceptara la compensación económica ofrecida tras la violación y que, además, ella le prometiera que algún día se vengaría. Benoît prepara un plan para acabar con Isa, pero fracasará en sus intenciones y morirá en el intento.

${ }^{23}$ Ibid., pp. 61-66.

${ }^{24}$ Sófocles. Edipo Rey. Edición en e-book. 


\section{Segundo caso de violación: La violación en tiempos de guerra (segunda violación de Isa)}

\section{Contexto y causa de la segunda violación de Isa}

La segunda violación de Isa transcurre en un lugar geográfico y bajo un contexto social muy distinto de la primera. Ella, a la edad de 27 años, trabaja como secretaria de una explotación agrícola, que utiliza esclavos como mano de obra, situada en una de las más prósperas de las colonias francesas: la isla de Santo Domingo.

Desde 1786 existía entre los colonos franceses una gran preocupación por las secretas reuniones nocturnas de los esclavos. Ellos pensaban que los esclavos planeaban una rebelión. Este temor a una revuelta estaba justificado si tenemos en cuenta que, según en el censo del año 1788, en Santo Domingo convivían 27.718 blancos y 21.803 personas de color libres, con una enorme población esclava que se estimaba en más de cuatrocientos mil o de quinientos mil individuos, según las fuentes. ${ }^{25}$

E1 14 de agosto de 1791 se supone que tuvo lugar la ceremonia de Bois-Caïman, ${ }^{26}$ que es considerada como el detonante del movimiento revolucionario que llevaría a la población de color, tras años de lucha, a la independencia de la colonia francesa de Santo Domingo; así nacería Haïti, «primera república negra salida de una guerra de independencia y de un movimiento de emancipación de los esclavos». ${ }^{27}$

La ceremonia de Bois-Caïman se considera, por tanto, como el inicio de la insurrección, que estallaría el 22 de agosto de 1791, que tuvo terribles consecuencias para los habitantes de los asentamientos rurales. Los esclavos atacaron los poblados aislados, torturando y matando a todas las personas que se encontraban a su paso. ${ }^{28}$ Esta revuelta se convirtió en una guerra entre las hordas de esclavos y el ejército regular destacado en la isla, compuesto por dos regimientos, los de Normandie y Artois. ${ }^{29}$

En ese domingo, 14 de agosto de 1791, Isa recorre a caballo las plantaciones de la región du Cap. Al anochecer es atraída por el sonido de un tambor y se dirige, bajo la lluvia, hasta el lugar de donde procede la música de percusión. Cuando percibe que está muy cerca del

25 Thiе́вaut, M. Le chemin de l'Atchafalaya. Tournai, 12bis, 2010, p. 20.

${ }^{26}$ Los historiadores no están de acuerdo en la fecha ni del lugar donde se celebró la ceremonia de Bois-Caïman. Ibid., pp. 15-25.

27 Ibid., p. 25.

28 «[Los esclavos] destruyeron mucho porque habían sufrido mucho. Sabían que mientras las plantaciones siguiesen en pie su destino consistiría en trabajarlas hasta caer reventados. No había más opción que destruirlas. Por sus amos habían conocido la violación, la tortura, la degradación y, a la menor provocación, la muerte. Retribuyeron con creces lo aprendido. James, C. Los jacobinos negros. Toussaint L'Ouverture y la revolución de Haiti. Madrid, Turner Fondo de Cultura Económica, 2003, p. 95.

${ }_{29}$ Тние́ваut, M. Op. cit., p. 24. 
objeto sonoro, deja su montura atada a un arbusto y camina, sin dejarse ver, hasta llegar al llano en el que se celebra la histórica ceremonia de Bois-Caïman bajo la enorme cúpula de un árbol Caïmitier (Caimito). Allí se concentran numerosos esclavos que realizan el sacrificio de un cerdo, ${ }^{30}$ mientras que un líder pronuncia un discurso en el que anuncia la voluntad de Dios que clama venganza contra el pueblo blanco.

\section{Puesta en escena de la segunda violación de Isa}

Isa abandona corriendo el lugar de la ceremonia, pero tropieza con tres hombres de color que la apresarán y la violarán. Bourgeon representa la escena de la agresión con solo dos viñetas integradas en una banda de tres cuyo tamaño es creciente de izquierda a derecha (FIG. 4). En la primera viñeta vemos volar, literalmente, la ropa de Isa bajo una intensa lluvia, lo que anuncia al lector las intenciones de los tres hombres; en la segunda viñeta se muestra en primer término el tronco de un árbol caído y al fondo la imagen, apenas perceptible, de Isa acostada en manos de sus agresores. Con la tercera viñeta llega la calma: un paisaje agrícola, plataneras bajo un cielo claro donde revolotean blancas mariposas. En la elipse entre la segunda y la tercera viñeta transcurre un espacio de tiempo impreciso que ni siquiera Isa es capaz de recordar. Ella llegará a casa de Congo, amante de color de Isa, con huellas de haber sufrido, en su cuerpo y su rostro, una enorme violencia. El cansancio y el agotamiento hace que Isa caiga desmayada en el umbral de la puerta de su amante secreto. Allí, ella dormirá inconsciente durante varios días. Bourgeon representa el paso del tiempo con viñetas consecutivas en las que se alternan la noche con el día, la lluvia con un cielo luminoso; mientras tanto, Isa recibirá los cuidados de la comunidad de la gente de color cercana a Congo.
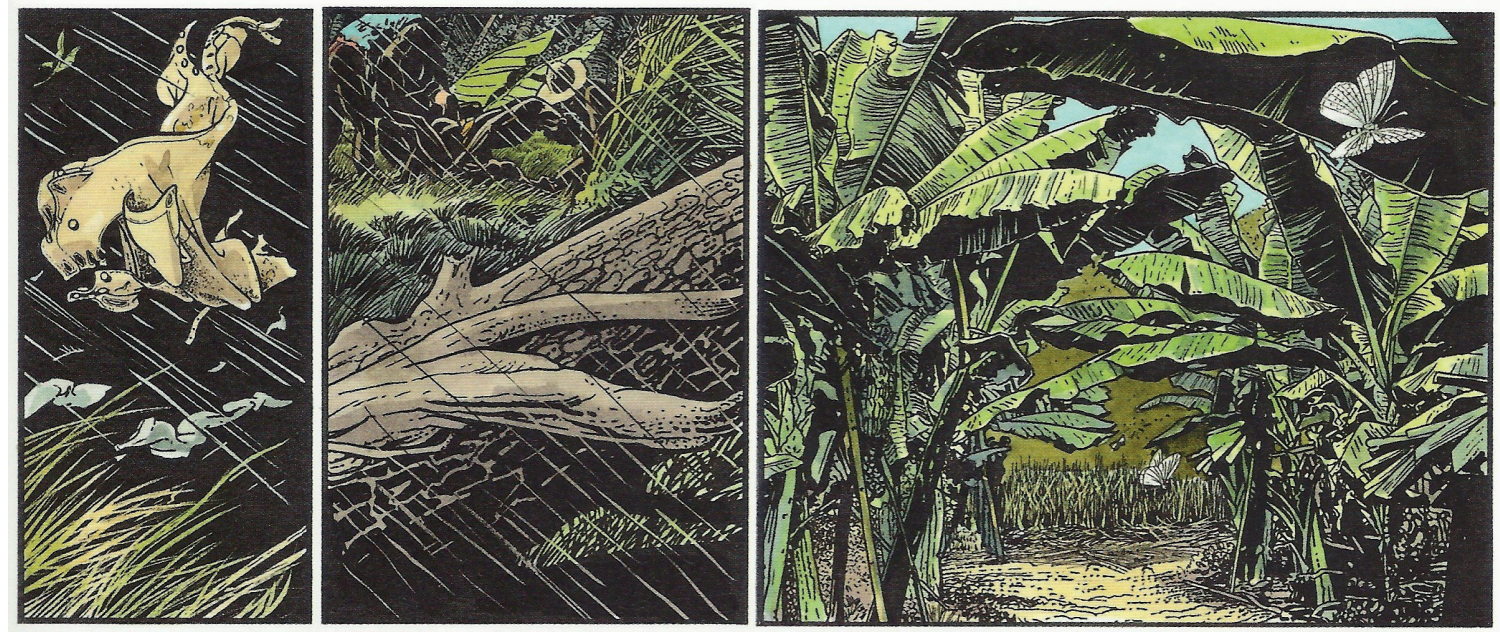

FIG. 4. La violación de Isa por un grupo de esclavos negros en la isla de Santo Domingo se escenifica en sola una viñeta llena de sombras (La petite Fille Bois-Caïman. Libro 1, 12bis, 2009, p. 73).

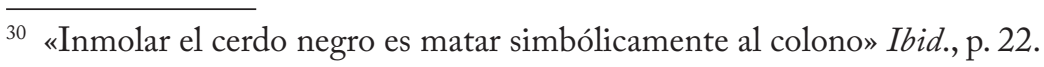




\section{Consecuencias de la segunda violación de Isa en un contexto de guerra}

Cuando Isa despierta toma conciencia de lo que le ha sucedido. Esto supone una doble tortura porque tiene que revivir, en cierta forma, la violencia a la que fue sometida por parte de los violadores. Recordar la agresión, asumir la violación y afrontar la vida bajo este estigma.

Bourgeon ha preferido no mostrar directamente el horror y el sufrimiento de Isa siendo violada, sino que el lector lo conozca a través de las heridas en su cuerpo y del relato que la propia víctima hace a Congo:

Nunca creí que debería de revivir esto... Ellos [los violadores] me dieron por muerta... Ya no sabía donde estaba ¿Choisel? ¿Lenormand? He caminado en círculos... varias leguas. Por una suerte increíble, he encontrado tu casa. ¿Maldita sea! Qué miedo he tenido.

[...] Mis veintisiete años se parecen a mis catorce [por su primera violación].

Estudios recientes señalan que el miedo a la muerte es el principal sentimiento que tienen las mujeres durante el asalto sexual. «Las víctimas afirmaban que lo que les inquietaba no era tanto la violación, sino el sentimiento de que después de la agresión les iban a matar». ${ }^{31}$

Congo aconseja a Isa que es mejor «callar y olvidarlo todo lo antes posible». Esta frase no es fortuita, sino que es el reflejo de la percepción de la violación en la sociedad en el Antiguo Régimen: esta pasa a ser una «violencia ignorada, rechazada a las zonas más oscuras de la conciencia colectiva, tan rápidamente negada que apenas se puede avistar». ${ }^{32}$

Sin embargo, ninguna mujer olvida que ha sido objeto de una violación. El paso del tiempo puede borrar los recuerdos más dolorosos pero, periódicamente, estos volverán a su mente produciéndole trastornos psicológicos difíciles de superar. Isa, seguramente, lo ha experimentado, pues esta es la segunda violación que padece, y lo manifiesta de forma inequívoca: «¿Olvidar? ¿Solo eso?... Incluso después de cien años me acordaré de ellos [los violadores]... A veces, ser mujer no es mejor que ser esclavo» (La Petite Fille de Bois-Caïman. Libro 1, p. 75).

La insurrección se convirtió en guerra e Isa, en la ficción, fue la primera víctima. Los hombres blancos de las plantaciones, en manos de los insurgentes, fueron torturados y asesinados; las mujeres eran violadas antes de matarlas. ${ }^{33}$ "La violencia conlleva violencia y - parece- ¡la justifica!». ${ }^{34}$ «Allí donde las subculturas de la violencia apoyen al violador, como en

31 Garrido, V. Op. cit., p. 102.

32 Vigarello, G. Op. cit., p. 49.

33 «[Las mujeres de los esclavos] habían sufrido incontables violaciones y ellos violaron ahora a todas las mujeres que cayeron en sus manos, muchas veces sobre el cuerpo de sus esposos que aún estaban desangrándose, o de sus padres, o de sus hermanos». James, C. Op. cit., p. 94.

34 Thiébaut, M. Op. cit. p. 25. 
el caso de contiendas nacionales, raciales o de clases, el violador será "normal", es decir, su conducta mostrará las características de la conducta normal». ${ }^{35}$

Debemos tener en consideración que, como definición «conceptual», «el único acto de guerra que se designa [como tal] es el conflicto entre soldados». ${ }^{36}$ En base a esta definición, cabría pensar que la guerra es solo cosa de hombres. Sin embargo sabemos que muchas de las víctimas de los conflictos bélicos son civiles y entre ellos están las mujeres. Además, el fin de una contienda no significa el cese de la violencia y la muerte sino que estas pueden perdurar durante meses o incluso años.

Las mujeres han sido, desde siempre, víctimas de los daños colaterales de la guerra. Valga como ejemplo el relato de Eurípides de Las Troyanas: una vez que ha caído la ciudad en mano de los griegos, las nobles troyanas sufrirán diferente suerte según su «valor» como mujer.

Hécula, reina de Troya, se interesa por la suerte que correrán sus hijas. Taltibio, mensajero de los griegos vencedores en la guerra, le contesta:

Taltibio: [A Casandra] la eligió para sí el rey Agamenon... [A Polixema] la han destinado al servicio dela tumba de Aquiles... [A la propia reina le anuncia su destino] Ulises, rey de Itaca, es tu dueño, y tú [Hécula] serás su esclava.

Hécula: Las vírgenes fueron para el deleite de mis enemigos, las arrancaron de mis brazos y no abrigo la más remota esperanza de volver a verlas. Y el último, mi mal más grave, es que vaya yo a Grecia, esclava y anciana, sufriendo intolerables trabajos. ${ }^{37}$

Lamentablemente, no tenemos que recurrir a la ficción histórica de tiempos remotos para tener ejemplos de la vulnerabilidad de la mujer en contiendas bélicas del mundo occidental:

Al final de la Segunda Guerra Mundial en Berlín 110.000 mujeres fueron violadas. Una estimación menos conservadora citan la cantidad de 900.000 mujeres violadas y maltratadas.

Según una comisión de investigación de la Unión Europea la violación en masa y la tortura sádica de mujeres en Bosnia-Herzegovina se realizó de forma sistemática como una misión... Las violaciones fueron concebidas en la estrategia de guerra serbia. ${ }^{38}$

Las violaciones en tiempos de guerra no provienen del hecho de que el hombre pudiera ser un ser violento por naturaleza que se reprime en tiempos de paz o de que exista una necesi-

35 Bauermeister, M. «Rapist, victims and society», en International Journal of Offender Therapy and Comparative Criminology, 21(3) (1977), pp. 238-248. Cit. en Garrido, V. Op. cit., p. 95.

36 Seifert, R. «Krieg und Vergewaltigung. Ansätze zu einer Analyse», en Sowi-Arbeitspapier, München (1993), n.o 76, p. 8. Disponible en http://www.mgfa-potsdam.de/html/einsatzunterstuetzung/downloads/ ap076.pdf?PHPSESSID $=92 \mathrm{bb} 8$

37 Eurípides. Las Troyanas. Edición en e-book.

38 Seifert, R. Op. cit., p. 2. 
dad apremiante de satisfacer un deseo sexual y que para ello empleen la violencia. «Las violaciones serían un fenómeno natural de la guerra y las mujeres los objetos naturales de esta». ${ }^{39}$

Si se parte de la idea, expresada más arriba, de que la guerra es - o era- cosa de hombres, cabría preguntarse: ¿por qué se produce esta violencia sobre las mujeres sometiéndolas a continuas violaciones, si ellas, normalmente, no suponen un peligro para la integridad de los soldados o para la logística bélica?

Una respuesta posible a estas preguntas sería que «las mujeres no son violadas porque ellas son enemigas sino porque son objeto de odio, el que caracteriza el inconsciente cultural y que en tiempos de crisis se actualiza». ${ }^{40}$

La violación de Isa fue un encuentro casual. Los agresores se hallaban en el lugar y en el momento oportuno para dar rienda suelta al odio que se expresa durante crisis opresoras y raciales. Isa reúne en su persona algunas de las características ideales para ser la primera víctima de la revuelta de los esclavos contra los colonos franceses de Santo Domingo. Ella es blanca (grupo opresor), secretaria de plantación agrícola (al servicio del poder esclavista) y mujer.

\section{Tercer caso de violación. La no resistencia de Mary a la agresión sexual}

\section{Contexto y causa de la violación de Mary}

Mary es una joven inglesa de origen burgués que se presenta, al inicio de la obra, como un personaje un tanto superficial, que sirve de complemento a la Isa intelectual, y de comportamiento irresponsable, frívolo o casi libertino.

La violación de Mary tendrá lugar en el barco negrero que transporta un ingente número de esclavos destinados a ser vendidos en las colonias de América.

La situación en el barco es muy complicada. Los esclavos se han amotinado y transitan libremente por la bodega, disponen de armas y sus maniobras ponen en peligro la estabilidad del barco que corre riesgo de hundirse.

La escena previa a la violación está narrada en una sola página que contiene un elevado número de viñetas, veinticuatro, en la que abundan los primeros planos con globos de extenso texto.

En las tres primeras viñetas, cuatro hombres reflexionan sobre la posibilidad que tienen de hundirse con el barco o de recibir un disparo de los esclavos amotinados (FIG. 5). De la viñeta cuarta a la sexta se produce un incidente fortuito que sirve de coartada a los marineros para agredir sexualmente a Mary. Ella, vestida con ropas de hombre pide permiso para

39 Ibid., p. 14.

${ }^{40}$ Ibid., p. 10. 

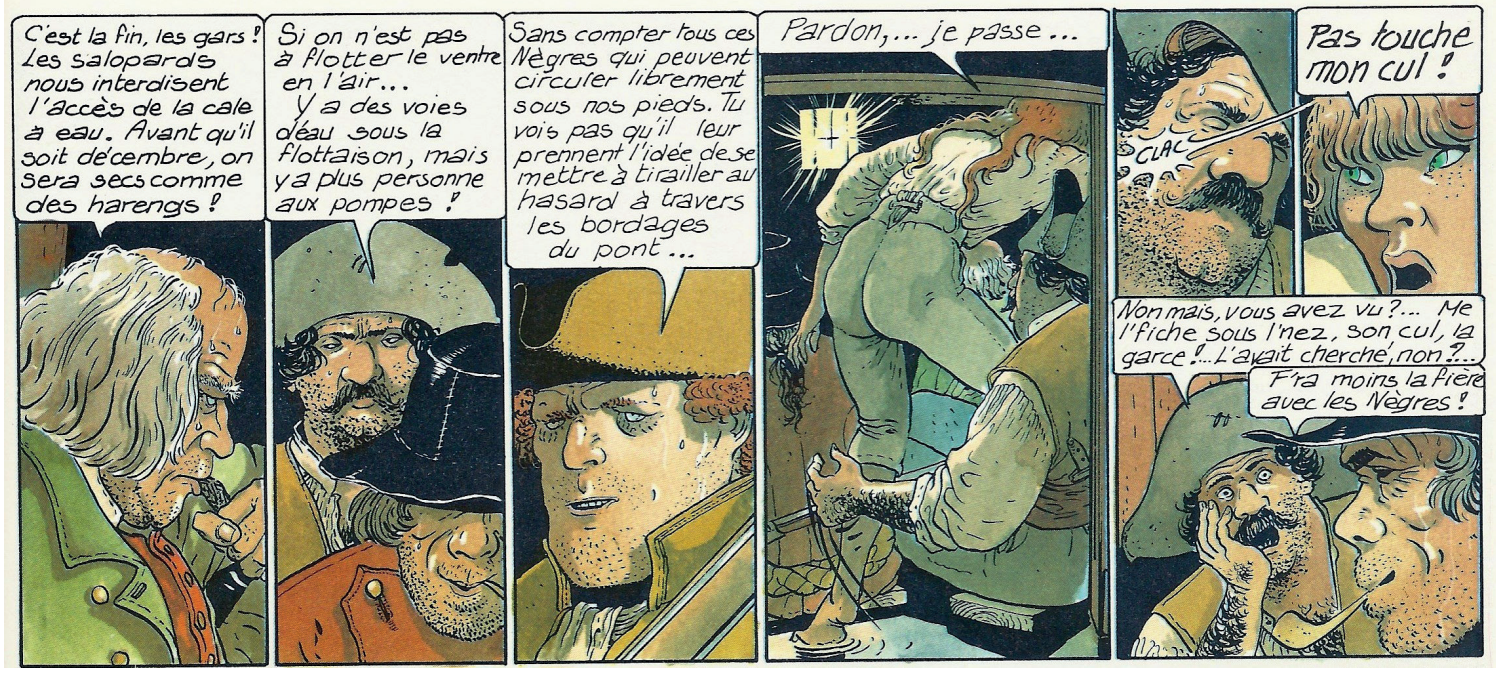

FIG. 5. Vestida de hombre, Mary se abre paso entre cuatro marineros en un estrecho habitáculo de un barco negrero. Este gesto es percibido como una provocación femenina por uno de los marineros que no duda en posar su mano sobre el cuerpo de Mary. Ella responde a la agresión con una bofetada (Le bois d'ébène. Glénat, 1984, p. 25).
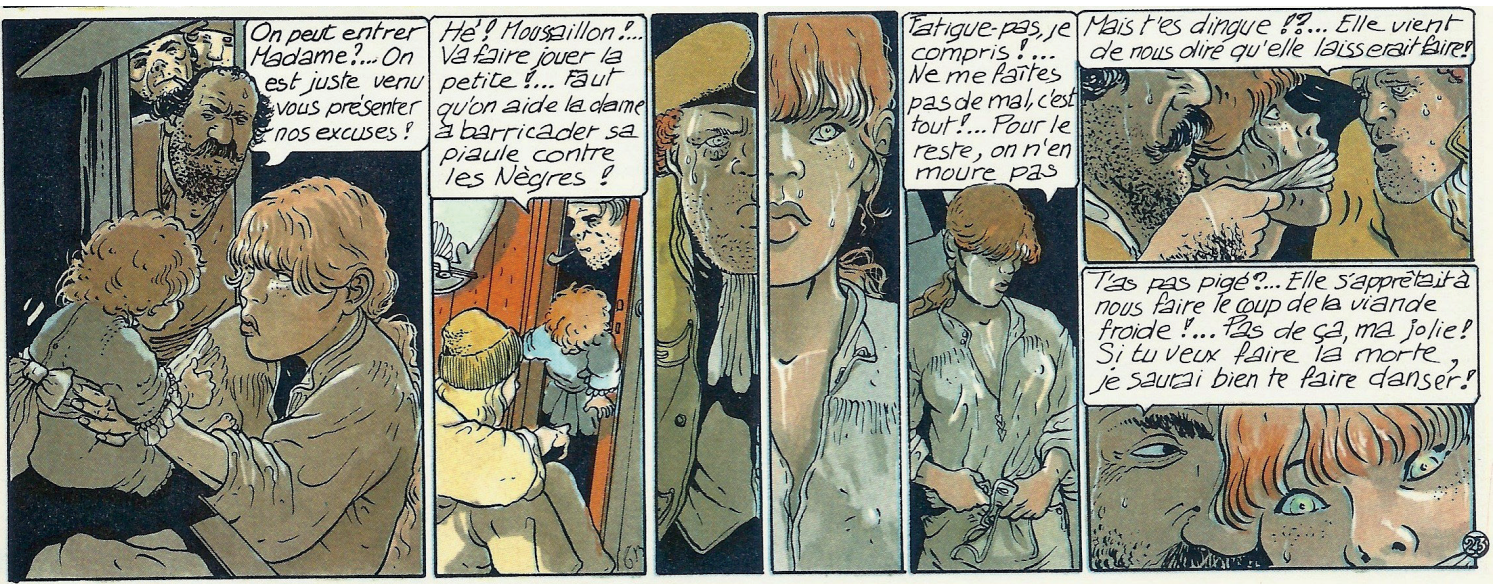

FIG. 6. Cuatro marineros irrumpen en el camarote de Mary con la intención de violarla. Ella ofrece no resistirse si no le hacen daño pero uno de los marineros desea una violación sexual agresiva (Le bois d'ébène. Glénat, 1984, p. 25).

pasar entre los cuatro hombres, que se encuentran en un estrecho habitáculo, y acceder a su camarote privado donde se encuentra su hija, Enora, de apenas unos meses de edad. Uno de los hombres ve en este gesto una provocación femenina y posa su mano sobre el cuerpo de la joven. Mary responde a este atrevimiento con una bofetada que hiere el orgullo del hombre. 
En las viñetas octava a undécima, los marineros traman la violación de Mary y sopesan los pros y los contras de esta acción. A continuación, de las viñetas duodécima a la decimoséptima, un jovencísimo grumete, que ha escuchado la conversación, advierte a los cuatro hombres de que podrían ser ahorcados sí hacen lo que planean, ya que Mary es la actual pareja del teniente que comanda el barco. Los marineros atemorizan al pequeño grumete y le hacen prometer que guardará silencio. Para encontrar el valor para emprender la violación y minusvalorar sus consecuencias, utilizan el razonamiento siguiente: «Perdidos por perdidos, aprovechemos antes que los negros hagan saltar el cascarón [del barco]».

La acción previa al asalto sexual se narra de la viñeta decimoctava a la vigésimo cuarta (FIG. 6). Los marineros irrumpen en el camarote de Mary con la disculpa de querer presentarle sus excusas por la ofensa de la que ha sido objeto. Su hija, Enora, es entregada en custodia al grumete que aguarda fuera de la habitación. Es curioso el pudor de los marineros a que la niña, que difícilmente podría entender el dolor ajeno o juzgar la violencia, sea testigo de la violación de su madre. Mary adivina la intención de los cuatro hombres y les propone no demorar el asalto a cambio de que no le hagan daño.

Durante el Antiguo Régimen, el sistema legal buscaba pruebas que pusieran de manifiesto resistencia contundente de la víctima frente al agresor sexual.

\begin{abstract}
Se necesitan protestas siempre audibles: si se prueba que solo se han realizado los primeros esfuerzos, no se trata de un caso de violación. Tienen que ser incluso extremos, constantes: el silencio siempre pone en duda la prueba hasta excluir la idea de la violación. La víctima debe mostrar que se ha resistido físicamente desde el principio al fin. ${ }^{41}$
\end{abstract}

Si esta resistencia no era percibida, se consideraba que la mujer había consentido o incluso provocado que ocurriera el contacto sexual. La apariencia jugaba un papel importante y podría enmascarar la propia violación en sí tras el manto de la lujuria o el pecado.

Porque el universo de la falta, el del pecado, constituye la base de las sentencias del Antiguo Régimen, la violencia no se destaca demasiado y la víctima de una violación es sospechosa... La mirada que cae sobre la transgresión moral obstaculiza la mirada que cae sobre la transgresión violenta... ${ }^{42}$

\title{
Motivo de la no resistencia de Mary durante la violación
}

Mary no opone resistencia a sus cuatro agresores. Esto se vería como una decisión irresponsable, pero su actitud tiene otra causa: el miedo. El miedo puede paralizar a la mujer que es objeto de una violación impidiéndole una defensa activa. Estudios recientes señalan que un notable porcentaje de mujeres que fueron violadas presentaban esta incapacidad de reacción defensiva frente al violador, como se verá más adelante.

${ }^{41}$ Vigarello, G. Op. cit., pp. 64-65.

${ }^{42}$ Ibid., p. 62. 
Cuando uno de los asaltantes pone una banda de tela en la boca de Mary para que no puedan ser escuchados sus lamentos de dolor, otro le recuerda que la mordaza es innecesaria porque ella ha dicho que se va a dejar hacer. El primer marinero no solo desean satisfacer sus instintos sexuales, sino que busca la sumisión de la mujer por la fuerza y el reconocimiento de la superioridad masculina: «Si tú [Mary] quieres hacerte la muerta yo sabré hacerte bailar». El dolor infringido a la mujer durante la violación forma parte del juego erótico como un ingrediente indispensable para que la violación sea perfecta.

Aquí estamos frente a un tipo agresor que se encuadra en la denominada «violación sexual-agresiva», que "para sentir excitación sexual el atacante debe infringir daño físico». ${ }^{43}$

Mary sufrió durante la violación maltrato físico, como muestra su nariz y labios sangrantes, pero, sobre todo, lo que sintió fue miedo: «es por eso por lo que no he gritado ni luché contra ellos».

La resistencia activa es considerada como una reacción «normal» durante la violación. Sin embargo, estudios han señalado que, igual que los animales, los humanos expuestos a una amenaza pueden reaccionar con un estado de inhibición motora temporal involuntaria conocida como Tonic Immobility (tanatosis) (TI de aquí en adelante, por las siglas en inglés). ${ }^{44}$

Lo que podría interpretarse como un consentimiento pasivo por parte de Mary durante la violación es en realidad una respuesta extendida en el mundo animal; es considerada como «una reacción defensiva adaptativa de la evolución para el ataque de un predador cuando la resistencia no es posible y otros recursos no están disponibles». ${ }^{45}$

La mayor parte de los estudios sobre TI en humanos se han realizado a partir de los testimonios de víctimas de violaciones sexuales y, en cierta medida, «se debe a que hay una presunción similar entre la violación sexual y el encuentro con depredadores». ${ }^{46}$

A partir de test aplicados a personas que han sufrido una violación sexual se ha construido una escala (TIS, Tonic Immobility Scale) para medir la TI que padece una persona durante el asalto sexual. Mediante la aplicación de este test se ha comprobado que de 298 mujeres examinadas, el 69,8\% tuvieron un TI significativo y el 47,7\% alcanzaron valores de TI extrema. ${ }^{47}$

Por lo tanto, la pasividad de Mary frente a los asaltantes no se debe a un acto irresponsable o de complacencia para evitar el dolor, sino a una inmovilidad debida al miedo.

${ }^{43}$ Garrido, V. Op. cit., p. 93.

${ }^{44}$ Möller, A., Söndergaard, H. P. y Helström, L. «Tonic immobility during sexual assault -a common reaction predicting post-traumatic stress disorder and severe depression», en Obstetrics E Gynaecology, n. ${ }^{\circ}$ 96 (2017), p. 932. Disponible en https://obgyn.onlinelibrary.wiley.com/doi/10.1111/aogs.13174

45 Ibid., p. 932.

46 Ibid., p. 933.

${ }^{47}$ Ibid., p. 935. 


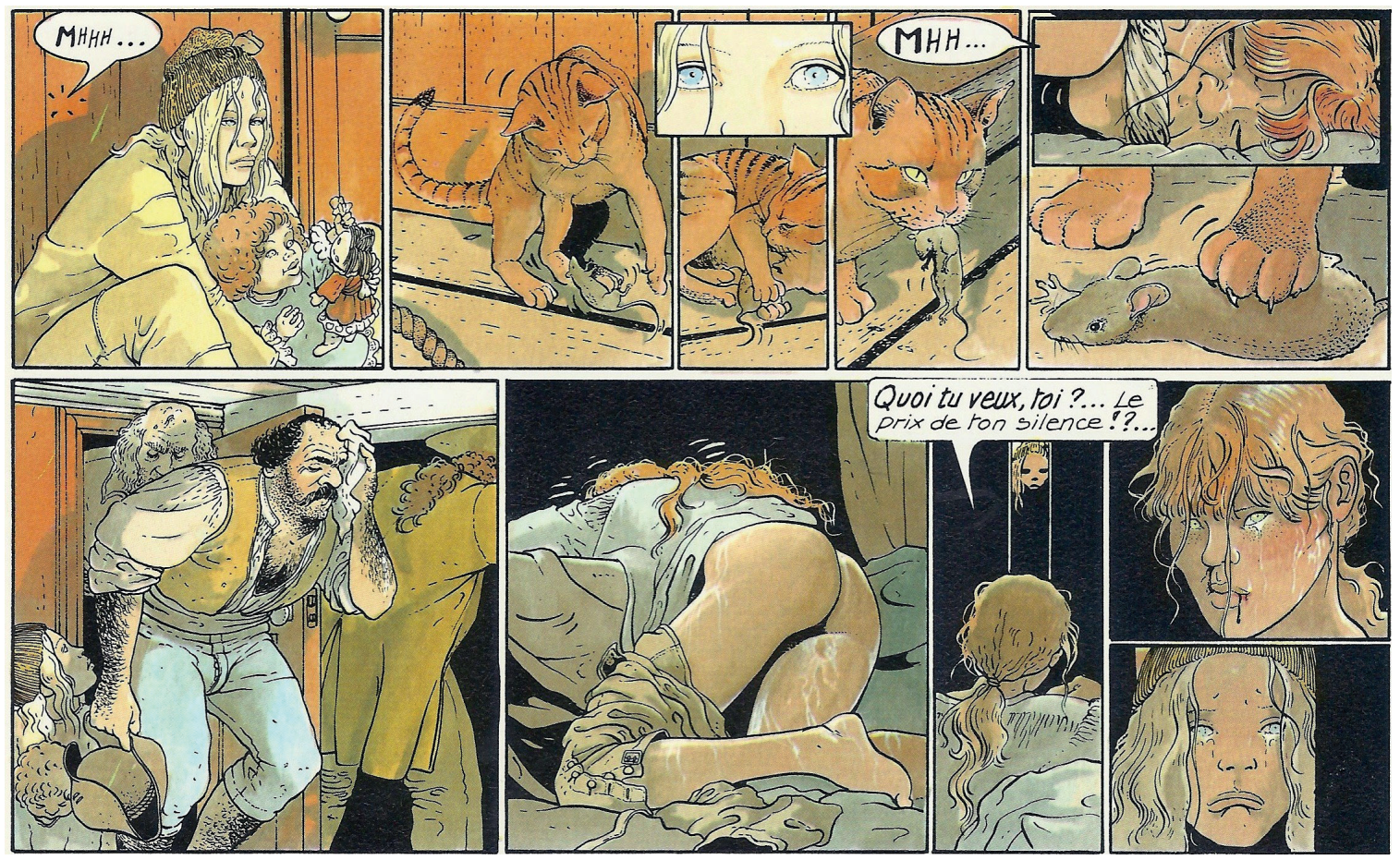

FIG. 7. La violación de Mary se narra a través de una metáfora visual en la que se presenta a un gato jugando con su presa. La asociación del predador con los violadores y de Mary con la presa es evidente. (Le bois d'ébène. Glénat, 1984, p. 26).

Bourgeon aleja al lector del lugar donde se está produciendo la violación y le lleva hasta el exterior de la puerta del camarote de Mary. La escena siguiente se desarrolla en una página integrada por un número elevado viñetas, veinticinco, dispuestas en cuatro bandas. La primera banda representa una metáfora de la violación de Mary (FIG. 7). En la primera viñeta, la tristeza del grumete contrasta con el aspecto risueño de Enora que juega con su muñeca, mientras un globo recoge el lamento de Mary ahogado por la banda de tela que tiene en la boca. En las viñetas siguientes de esta primera banda, se ve como un gato juega con un ratón. El gato representa la fuerza de los violadores y el ratón la debilidad y el abandono de Mary. Las dos últimas viñetas, dispuestas verticalmente, refuerzan la relación entre las dos víctimas (Mary y el ratón).

\section{Consecuencias de la violación de Mary}

En la segunda banda de viñetas, cuando los violadores salen del camarote de Mary, el grumete se asoma a la puerta para devolver la niña a Mary (FIG. 7). Ella dice de forma abrupta: «¿Qué quieres? El precio de tu silencio». Para una mujer violada es mejor ocultar la afrenta que verse expuesta al juicio de los demás, porque puede ser acusada de incitar y provocar la violación. 


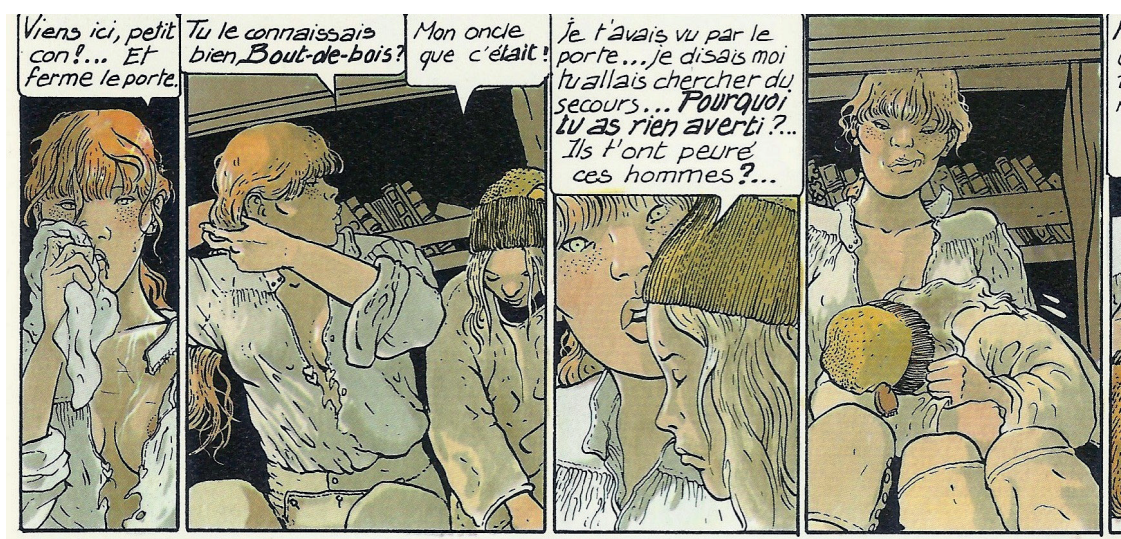

Moi aussi, ils miont pouvanté. C'est pour sa je pas crié, ni
tabasse' contre eux. Je te rancune pas trop, tu sais?. Ecoute un peu quai se voudrais te dire:...

Latête d'un homme, Fais comme moi!...Avant c'est toute petite:... un mois, j'aurai tout oublié. avec des regrets jusqu'd l'odeurde.ces inutiles qui affreux bonshommes... pourriturent la cervelle...
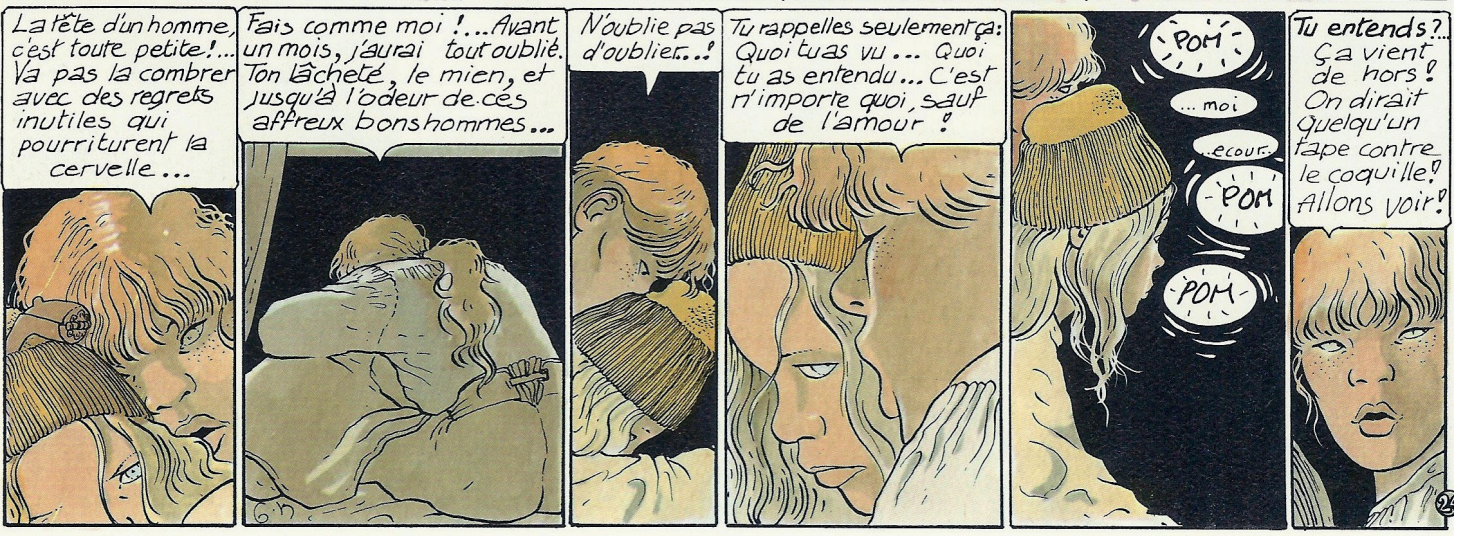

FIG. 8. Mary recrimina al pequeño grumete por no pedir ayuda para evitar su violación. El miedo ha paralizado a los dos. Mary se sobrepone y trata de calmar al grumete, a pesar de la violencia a la que ha sido sometida, con un alegato en el que separa el amor libertario de la violación sexual (Le bois d'ébène. Glénat, 1984, p. 26).

En la tercera banda de viñetas, Mary recrimina al grumete no haber ido a buscar ayuda, pero se da cuenta de que el niño está atemorizado por haber sido amenazado por los violadores; el grumete se siente culpable y comienza a llorar en el regazo de Mary (FIG. 8). Es en ese momento cuando ella pronuncia un breve alegato en el que la condición de mujer ultrajada se eleva por encima de la fortaleza de los hombres-predadores, donde se separa el concepto abstracto del amor, como acto amoroso, del acto sexual practicado bajo la violencia.

La cabeza de un hombre es muy pequeña... No vamos a llenarla con lamentos inútiles que pudrirán el cerebro... Haz como yo. Antes de un mes, habré olvidado todo. Tu cobardía, la mía, y hasta el olor de estos terribles hombrecillos... ¡No olvides, olvidar! Recuerda solo esto: Lo que has visto... lo que has escuchado, es cualquier cosa, excepto el amor» (Le bois d'ébène, p. 26).

El personaje de Mary como una imagen espejo de la mujer frívola, inconsciente e incapaz de asumir sus propias responsabilidades, cae hecho añicos y se presenta ahora como un ser 
cuyas ideas trascienden la inmanencia a la que pretendían reducirla sus agresores: un objeto sexual. «A pesar de la violencia de la que es víctima, ella continuará creyendo en su aspiración libertaria del amor». ${ }^{48}$

Cuando Mary sale de su camarote, se encuentra con sus cuatro agresores que, lejos de avergonzarse de su comportamiento, se permiten burlarse de ella. Es la falta de conciencia del daño físico y psicológico causado lo que oculta, a sus ojos, la violencia. Esta es una forma de negar a la mujer su condición de sujeto, ya que la representación de la feminidad en la conciencia colectiva, en el Antiguo Régimen, no contempla al agresor sexual como violador. Este término no existía como tal sino que se denominaba «autor de violación». ${ }^{49}$

«El acto de la violación es un acto agresivo, el cual responde a unos roles y una ideología social que lo mantiene impune $y$, en este sentido, lo fomenta». ${ }^{50} \mathrm{La}$ falta de conciencia de los agresores de Mary está plenamente justificada dentro del contexto histórico: ellos solo temerán ser acusados y condenados, pero nunca se sentirán culpables.

\section{Conclusiones}

En Los pasajeros del viento se incluyen escenas de desnudos y de contenido sexual. Su autor, François Bourgeon, no esquiva la representación gráfica de un acto sexual siempre que este sea consentido por los intervinientes. Sin embargo, en los tres casos de violación que hemos analizado en este artículo, el autor ha procurado sugerir más que mostrar explícitamente el momento de la agresión. Para evitar una patente escenificación de la violación Bourgeon utiliza tres recursos: La elipsis, la escenificación breve y difusa y, finalmente, la metáfora. Con la elipse empleada en la primera violación de Isa (caso primero), el lector sabe que la violación ha ocurrido, pero no puede precisar ni el cómo ni cuánto tiempo duró la agresión. El cómo, en este caso, podría ser una exhibición innecesaria de recreación de la violencia de género, y el tiempo transcurrido, como hemos visto, se sugiere a través de la iluminación. En la segunda violación de Isa (caso segundo) la escenificación breve, reducida a una sola viñeta en la que los personajes se sitúan en un lejano segundo plano, y con un dibujo lleno de sombras, el autor pretende turbar al lector, pero no crear un ambiente de complicidad de la violencia contra las mujeres. La metáfora (caso tercero) que equipara la violación de Mary con el juego de un predador con su presa (gato y ratón) configura una estructura narrativa de acciones paralelas en las que se omite, parcialmente, una de las partes (la violación). Bourgeon ha preferido ocultar al «violador sexual agresivo [que] para sentir excitación sexual... debe infringir daño físico» ${ }^{51}$ pero no por ello la escena deja de expresar el dramatismo traumático de la violación.

\footnotetext{
48 Pierpont, J. «Esclavage et condition feminine», en Les Cabiers de la Bande Dessinée, n. ${ }^{\circ} 65$ (1985), p. 24.

49 Vigarello, G. Op. cit., p. 280.

50 Garrido, V. Op. cit., p. 108.

51 Ibid., p. 97.
} 
Las denuncias por violación eran escasas durante el Antiguo Régimen y las condenas eran aún más limitadas. ${ }^{52}$ La víctima solía ser la primera sospechosa y se tendía a creer que el acto sexual era mayoritariamente aceptado voluntariamente por la mujer. Para ello se esgrime que «la violación intentada por un hombre solo sobre una mujer resuelta sería imposible por meros principios físicos, el vigor femenino basta para la defensa; la mujer dispone siempre de medios suficientes». ${ }^{53}$

Sin embargo, un elemento común en las violaciones analizadas es que, en los tres casos, están perpetradas por un grupo de varones que, curiosamente, pertenecen a tres estamentos sociales bien diferenciados. ${ }^{54}$ En el primer caso, entre los actores hay nobles y oficiales de la marina; en el segundo, son esclavos de color; y, finalmente, en el tercero, son gente de clase baja, marineros mercantes. Esta transversalidad en clases sociales pone de manifiesto que la violencia contra la mujer no está asociada a un determinado nivel social o cultural, sino que se presenta allí donde existe un sentimiento de desprecio hacia la condición femenina. «La violación no es una expresión agresiva de la sexualidad sino una expresión sexual de la agresividad. No sirve como un objetivo sexual en la psique del violador sino como la articulación de ira, fuerza y dominio sobre una mujer». ${ }^{55}$

A pesar de que los textos jurídicos agravan los hechos cometidos con la ayuda de varias personas, «los hechos denunciados a este respecto son confusos, las responsabilidades no se prueban suficientemente, de modo que la existencia de un grupo de acusados parece favorecer sordamente el anonimato y la confusión». ${ }^{56}$ Lamentablemente, en este aspecto no hemos mejorado; en la actualidad este tipo de violaciones colectivas continúa produciéndose y ejemplo de ello son las violaciones acaecidas en la noche de fin de año en Colonia (Alemania, 2016) o en la fiesta de los Sanfermines (España, 2016).

Otro elemento común en los tres casos de violación es la inclinación de las víctimas a guardar silencio por temor al rechazo y a verse envueltas en la infamia del deshonor: «esta situación se agudiza hasta el límite en el Antiguo Régimen por un conjunto de referencias culturales, morales y sociales transformadas en haz de efectos convergentes». ${ }^{57}$

La ordenanza jurídica del Antiguo Régimen disponía de normas que posibilitaban la condena del violador, pero estas no se aplicaban con rigor, por lo que las condenas eran muy

52 Vigarello, G. Op. cit., pp. 47-49.

53 Ibid., p. 69.

${ }^{54}$ Es una lástima que en Los pasajeros del viento no existan elementos sustanciales para ahondar en la diferencia de origen social de las protagonistas, una aristócrata francesa y una burguesa inglesa, dada la relevancia que tuvieron la nobleza en Francia y la burguesía en Inglaterra en siglo xviII. Sin embargo, Isa y Mary no viven como aristócrata y burguesa, respectivamente, sino como pasajeras de un barco del comercio triangular en el que convive la clase dirigente (militares, religiosos, médicos etc.), la clase trabajadora (los marineros) y la clase esclava.

55 Seifert, R. Op. cit., p. 3.

56 Vigarello, G. Op. cit., p. 45.

57 Ibid., p. 42. 
escasas, de ahí que las víctimas renunciaran a ejercer sus derechos legales. Isa no podía denunciar a un miembro de la nobleza cuyo padre es además su benefactor; tampoco podía denunciar a los esclavos negros que la violaron porque socialmente sería repudiada; Mary no se resistió a la violación de los marineros debido a lo que hoy sabemos que se denomina Tonic Immobility, provocada por el miedo, lo que se interpretaría como que el acto fue consentido.

Si bien una amplia tolerancia ante la violación durante el Antiguo Régimen ocultaba la violencia y silenciaba a las mujeres, hoy, en el occidente europeo, debido a un modo de vida más libre e independiente de la mujer, a la movilización feminista y a una mayor concienciación de una parte de la población masculina, las víctimas de violación sexual no aceptan ser relegadas al ostracismo y al silencio, como Isa y Mary, sino que denuncian a sus agresores y llegan más lejos al evidenciar el «acoso sexual», ${ }^{58}$ aún presente en la vida social y laboral de las mujeres, con objeto de acercar cada vez más los derechos de igualdad en la relación hombre-mujer.

$58 \mathrm{El}$ «acoso sexual» establecido en el Código Penal de 1992 en sus artículos 222-23. Algunos parlamentarios han clasificado de «no jurídica» la noción de acoso, o algunos de sus defensores le han reconocido un alcance ante todo simbólico (las leyes simbólicas son las que marcan los cambios. Se crea un interdicto y la transgresión será castigada)... La sociedad americana es un ejemplo extremo... que ilustra una intromisión cada ver mayor de la ley en los gestos privados, hasta el punto de castigar algunas veces la mera «intención sexual» o incluso el mero visual harassment (las miradas demasiado insistentes dirigidas a alguien). Un juez de Mineápolis pensó que lo adecuado era codificar en menos de nueve segundos el tiempo tolerable de mirada dirigida a una mujer. Ibid. pp. 340-342. 


\section{Bibliografía}

Echeburua, E., Corral, P., Sarasua, B. El impacto psicológico en las víctimas de violación. Departamento de Personalidad, Evaluación y Tratamientos Psicológicos, Universidad del País Vasco (sin fecha), Disponible en https://www.ehu.eus/documents/1736829/2028519/08+-+Impacto+psicologico.pdf

EuRípides. Las troyanas. Edición en e-book.

García, A. Lectura de los pasajeros de viento desde una perspectiva feminista. Cuco, Cuadernos de cómic, n. ${ }^{\circ} 8$ (2017), pp. 55-82. Disponible en http://cuadernosdecomic.com/docs/ revista8/Lectura de Los pasajeros del viento.pdf

Garrido, V. «Psicología de la violación», en Estudios de psicología, Universidad de Valencia, n. 38 (1989). Disponible en https://es.slideshare.net/sexxar/66041-fases-de-unaviolacion

Goncourt, E. y Goncourt, J. La femme au dix-huitième siécle, Paris, G. Charpentier, Éditeur, 1882.

Hamel, C. et al. «Viols et agressions sexuelles en France: premiers résultats de l'enquête Virage», en Population E̋ Sociétés, n. ${ }^{\circ} 538$ (2016). Disponible en https://www.ined.fr/ fichier/s rubrique/25953/538.population.societes.2016.novembre.fr.pdf

James, C. Los jacobinos negros. Toussanint L'Ouverture y la Revolución de Haití. Madrid, Turner Fondo de Cultura Económica, 2003.

Matthews, S. «El cuerpo apariencia y sexualidad», en Duby, G. y Perrot, M. (ed.). Historia de las Mujeres 3. Del Renacimiento a la edad moderna. Madrid, Taurus Minor, 1993.

Möller, A., Söndergaard, H. P., Helström, L. «Tonic immobility during sexual assault - a common reaction predicting post-traumatic stress disorder and severe depression", en Obstetrics E Gynaecology, n. 96 (2017). Disponible en https://obgyn.onlinelibrary.wiley.com/doi/10.1111/aogs.13174

Pierpont, J. «Esclavage et condition feminine», en Les Cahiers de la Bande Dessinée, n.o 65 (1985), pp. 23-25.

Seifert, R. «Krieg und Vergewaltigung. Ansätze zu einer Analyse», en Sowi-Arbeitspapier, München (1993), n. ${ }^{\circ}$ 76. Disponible en http://www.mgfa-potsdam.de/html/einsatzunterstuetzung/downloads/ap076.pdf?PHPSESSID $=92 \mathrm{bb} 8$ 
Slomanis, B. La morale féminine dans «Delphine» et «Corine» de Madame de Staël. [Tesis doctoral]. Mcgill University, Montreal, 1990.

Sonnet, M. «La educación de una joven», en Duby, G. y Perrot, M. (ed.). Historia de las Mujeres 3. Del Renacimiento a la edad moderna. Madrid, Taurus Minor, 1993.

Sófocles. Edipo Rey. Edición en e-book.

Thiе́ваuт, M. Le chemin de l'Atchafalaya. 12bis, Tournai, 2010.

VIgarello, G. Historia de la violación: siglos XVI-XX. Madrid, Ediciones Cátedra, Universitat de València, 1999. 